\title{
Antioxidant and Sensorial Properties of Polyfloral Honey with Dried Apricots after One Year of Storage
}

\author{
Jelena Vulić, Jasna Čanadanović-Brunet, Gordana Ćetković, \\ Sonja Djilas, and Vesna Tumbas Šaponjac
}

Faculty of Technology, University of Novi Sad, Bulevar cara Lazara 1, 21000 Novi Sad, Serbia

Correspondence should be addressed to Jelena Vulić; jvulic@uns.ac.rs

Received 13 January 2015; Revised 13 February 2015; Accepted 16 February 2015

Academic Editor: Ana B. Martin-Diana

Copyright (C) 2015 Jelena Vulić et al. This is an open access article distributed under the Creative Commons Attribution License, which permits unrestricted use, distribution, and reproduction in any medium, provided the original work is properly cited.

Total phenol (TPh) and flavonoid (TFd) contents, antioxidant and sensorial properties of polyfloral (PH), and polyfloral honey after one year of storage (PHs) with dried apricots (20,30, and 40\%) were evaluated. In comparison to honey, TPh increased 1.86 times for PH40. After storage time, TPh of PH40s increased slightly lower (1.77 times), compared to PHs. TFd slightly increased, approximately 3.23-fold, from PH to PH40, while PHs showed increase of 5.15-fold for PH40s. Antioxidant activity increased with increasing concentration of apricots in honey. $\mathrm{EC}_{50}{ }^{\mathrm{OH}}$ varied from 3.36 for $\mathrm{PH}$ to $2.29 \mathrm{mg} / \mathrm{mL}$ for $\mathrm{PH} 40$ and from 3.48 for PHs to $2.68 \mathrm{mg} / \mathrm{mL}$ for PH40s; $\mathrm{EC}_{50}{ }_{\mathrm{DPH}}$ ranged from 30.60 for PH to $14.95 \mathrm{mg} / \mathrm{mL}$ for PH40 and from 31.22 for PHs to $17.43 \mathrm{mg} / \mathrm{mL}$ for PH40s; $\mathrm{RP}_{0.5}$ ranged from 66.37 for PH to $31.83 \mathrm{mg} / \mathrm{mL}$ for PH40 and from 67.99 for PHs to $35.03 \mathrm{mg} / \mathrm{mL}$ for PH40s. Statistical analysis suggested that TPh and TFd were associated with antioxidant activity and colour. Sensory parameters, before and after storage, indicated very good sensory qualities. Phenolic composition, antioxidant capacity, and sensory properties were promoted after addition of dried apricots and these parameters stayed improved, since antioxidant compounds present in dried apricots aided in maintenance of honey properties along one year of storage.

\section{Introduction}

Honey is essentially a concentrated aqueous solution of inverted sugar, but it also contains a very complex mixture of other saccharides, enzymes, amino and organic acids, polyphenols, carotenoid-like substances, Maillard reaction products, vitamins, and minerals [1]. Numerous flavonoids (such as apigenin, pinocembrin, pinobanksin, kaempferol, quercetin, galangin, chrysin, and luteolin) and phenolic acids (caffeic, gallic, cinnamic, protocatechuic, p-coumaric, and chlorogenic acids) were identified in honey samples [2]. Many authors demonstrated that honey serves as a source of natural antioxidants, which are effective in reducing the risk of heart disease, cancer, immune-system decline, cataracts, different inflammatory processes, and so forth [3]. Honey has been reported to be effective against enzymatic browning of fruits and vegetables [4] and oxidative deterioration of some foods [5] and in controlling the growth of or eliminating foodborne pathogens [6]. On account of its high nutritional value (303 kcal/100 g honey) and fast absorption of its carbohydrates, honey is a food suitable for humans of every age. It is particularly recommended for children and sportsmen and by itself or associated with appropriate therapies, honey can help to improve the organism efficiency of the elderly and invalids [7].

Generally, honeys are classified as monofloral or polyfloral. Monofloral honeys are produced by one plant species containing predominantly its nectar with minor nectar contributions from other botanical origins. Polyfloral honey has several plant sources, none of which is predominant. In practical terms it can be considered as a blend of several monofloral honeys with significant nectar or honeydew contributions from different plants [2]. Physicochemical, sensory, and health-protective characteristics of honey depend strongly on the plant species from which the nectar or the honeydew was collected, as well as climatic and environmental conditions, and processing methods $[1,8]$. In Serbia, honey is usually used in the original form and as comb honey but also enriched with 
pollen, propolis, royal jelly, or other primary bee products. Besides these types of honey, honey with nuts and dried fruits is also prepared and consumed as a tasty dessert.

Drying of foods is particularly important for handling and distribution of raw materials with high moisture content and limited shelf-life such as fruits and vegetables. The main objective of drying of food products is to remove free water to a level where microbial spoilage is reduced and where a shelf stable, less perishable product is ensured [9]. Dried fruits represent a relatively concentrated form of fresh fruit whereby moisture removal confers increased shelf life. Dried fruits have higher total energy, nutrient density, fibre content, and often significantly greater antioxidant activity compared with fresh fruits as a consequence of concentration [10]. Apricot (Prunus armeniaca L.) is member of the rose family (Rosaceae) and closely related to plum, peach, cherry, and almond [11]. This fruit is a rich source of antioxidant molecules: phenolics comprising both hydro- and lipophilic components, lipid-soluble carotenoids, and water-soluble vitamin $\mathrm{C}$, which contribute significantly to their taste, colour, and nutritive values [12]. Apricot is consumed as fresh fruit and processed to jam, compote, dried apricot, and well-known apricot brandy. Dried apricots have a far greater nutritional value than the fresh ones because all nutrients are concentrated [13].

The aim and purpose of the present study was to evaluate total phenolic and flavonoid contents, antioxidant activity, and sensory characteristics of polyfloral honey with dried apricots before and after one-year storage. Antioxidant activity was determined by three different assays: 2,2-diphenyl1-picrylhydrazyl (DPPH) and hydroxyl $\left({ }^{\circ} \mathrm{OH}\right)$ free radical scavenging assays and reducing power (RP).

\section{Material and Methods}

2.1. Chemicals and Reagents. The chemicals used for these investigations were Folin-Ciocalteu reagent (Fluka Chemical Co., Buchs, Switzerland), trichloroacetic acid, 2,2-diphenyl-1pichrylhydrazyl, 5,5-dimethyl-1-pyroline- $N$-oxide (DMPO), flavonoids, and phenolic acid (Sigma Chemical Co., St. Louis, Mo, USA). All other chemicals and reagents were of the highest analytical grade, obtained from J.T. Baker (Deventer, Holland). The total phenolic, flavonoid, DPPH free radical scavenging assays and reducing power were determined using an UV-1800 spectrophotometer (Shimadzu, Kyoto, Japan), while the antioxidant activity against reactive hydroxyl radicals was evaluated by electron spin resonance (ESR) spectroscopy (Bruker 300E ESR spectrometer, Rheinstetten, Germany).

2.2. Honey and Dried Apricots Samples. The honey samples with dried apricots are prepared from polyfloral $(\mathrm{PH})$ honey (obtained from the honeybee farm "Simonović", Belgrade, Serbia). Dried apricots (produced by Florida Bel d.o.o., Zemun, Serbia) were cut into four pieces and ground in domestic food processor (Bosh, Germany) and added to the honey in three different mass concentrations $(20 \%$, PH20; $30 \%$, $\mathrm{PH} 30$; and $40 \%$, $\mathrm{PH} 40$ ).
2.3. Total Phenolic Content (TPh). Total phenolics were determined spectrophotometrically by the Folin-Ciocalteu method [14]. The content of total phenolics was expressed as $\mathrm{mg}$ of gallic acid equivalents per $100 \mathrm{~g}$ of honey sample ( $\mathrm{mg}$ GAE/100 g).

2.4. Total Flavonoid Content (TFd). Total flavonoids were measured by the aluminium chloride spectrophotometric assay [15]. Total flavonoid content was expressed as mg of rutin equivalents per $100 \mathrm{~g}$ of honey sample (mg RE/100 g).

2.5. Hydroxyl Radical Scavenging Activity. Hydroxyl radicals were generated in the Fenton reaction system obtained by mixing DMPO $(200 \mu \mathrm{L}, 112 \mathrm{mM}), \mathrm{H}_{2} \mathrm{O}(200 \mu \mathrm{L}), \mathrm{H}_{2} \mathrm{O}_{2}$ $(200 \mu \mathrm{L}, 2 \mathrm{mM})$, and $\mathrm{Fe}^{2+}(2 \mu \mathrm{L}, 30 \mathrm{mM})$ (control). The influence of honey samples, at the appropriate range of concentrations $(1.0-10.0 \mathrm{mg} / \mathrm{mL})$, on the formation and stabilization of hydroxyl radicals was investigated by ESR spin trapping method. The ESR spectra were recorded after $2.5 \mathrm{~min}$, with the previously defined spectrometer settings (field modulation $100 \mathrm{kHz}$, modulation amplitude $0.226 \mathrm{G}$, receiver gain $5 \times 105$, time constant $80.72 \mathrm{~ms}$, conversion time $327.68 \mathrm{~ms}$, center field $3440.00 \mathrm{G}$, sweep width $100.00 \mathrm{G}, x$ band frequency $9.64 \mathrm{GHz}$, power $20 \mathrm{~mW}$, and temperature $23^{\circ} \mathrm{C}$ ). Hydroxyl radical scavenging activity of honey samples $\left(\mathrm{SA} \cdot{ }_{\mathrm{OH}}\right)$ was defined as

$$
\mathrm{SA} \cdot \mathrm{OH}(\%)=100 \times \frac{\left(h_{0}-h_{x}\right)}{h_{0}},
$$

where $h_{0}$ and $h_{x}$ are the heights of the second peak in the ESR spectrum of DMPO-OH spin adduct of the control and the sample, respectively.

2.6. DPPH Free Radical Scavenging Assay. Honey samples were dissolved in methanol, and each sample $(1.5 \mathrm{~mL})$ or methanol (1.5 mL, blank) was mixed with DPPH solution in methanol $(3 \mathrm{~mL}, 0.02 \mathrm{mg} / \mathrm{mL})$ in appropriate range of investigated concentrations $(5-50 \mathrm{mg} / \mathrm{mL})$. The mixtures were left for $15 \mathrm{~min}$ at room temperature and then the absorbances were measured at $517 \mathrm{~nm}$ against reference mixtures that were prepared in the similar manner, by replacing the DPPH solution with methanol. The ability of honey samples to scavenge $\mathrm{DPPH}$ radicals, $\mathrm{SA}_{\mathrm{DPPH}}$. value, was calculated using the following equation:

$$
\mathrm{SA}_{\mathrm{DPPH}^{\cdot}}(\%)=100 \times \frac{\left(A_{0}-A_{x}\right)}{A_{0}},
$$

where $A_{0}$ and $A_{x}$ are the absorbances of the blank and the sample, respectively.

2.7. Reducing Power. The solution of honey samples (2.5$100 \mathrm{mg})$ in distilled water $(1 \mathrm{~mL})$ or distilled water $(1 \mathrm{~mL}$, blank) was mixed with phosphate buffer $(1 \mathrm{~mL}, \mathrm{pH}$ 6.6) and potassium ferricyanide, $\mathrm{K}_{3}\left[\mathrm{Fe}(\mathrm{CN})_{6}\right],(1 \mathrm{~mL}, 1 \%)$. The mixture was incubated at $50^{\circ} \mathrm{C}$ for $20 \mathrm{~min}$ and then rapidly 
cooled. Following this, trichloroacetic acid ( $1 \mathrm{~mL}, 10 \%)$ was added and the mixture was then centrifuged at $3000 \mathrm{rpm}$ for $10 \mathrm{~min}$. An aliquot $(2 \mathrm{~mL})$ of the upper layer, mixed with distilled water $(2 \mathrm{~mL})$ and $\mathrm{FeCl}_{3}(0.4 \mathrm{~mL}, 0.1 \%)$, was left to stand for $10 \mathrm{~min}$. The absorbance of the mixture was measured at $700 \mathrm{~nm}$ against the blank.

2.8. Sensory Analysis. Sensory analysis was conducted according to the general guidelines regarding the design of test rooms [16], general sensory analysis guidance [17], and training of assessors [18, 19]. Sensory evaluation was carried out by seven experienced panelists selected from previously trained academic staff of the Faculty of Technology, Novi Sad. Drinking water was provided for cleansing the palate between each sample. Sensory profiling was performed using a generic descriptive analysis technique, according to [20]. Sensory evaluation included the selected representative properties of honey samples: density, intensity of color, aroma, and odour. These properties were evaluated using a 3-point method. Marks were given based on the scale from 0 "unacceptable product" to 3 "optimal quality level."

2.9. Statistical Analysis. All analyses were run in triplicate and the results were expressed as means \pm standard deviation (SD) except for sensory analysis $(n=7 \times 7)$. Statistical analyses were done by using Microsoft Office Excel 2007 software. Significant differences were calculated by ANOVA test and least significant difference (LSD) test $(P<0.05)$.

\section{Results and Discussion}

Polyfloral honey $(\mathrm{PH})$ was used to prepare honey samples with different amount $(20 \%, 30 \%$, and $40 \%)$ of dried apricots (PH20, PH30, and PH40). Also, the changes in the antioxidant compounds and antioxidant capacity of the polyfloral honey samples after one-year storage (PHs, $\mathrm{PH} 20$ s, $\mathrm{PH} 30$ s, and $\mathrm{PH} 40 \mathrm{~s}$ ) were investigated. The comparative evaluation of the polyphenolic composition of honey samples was based on three representative indices: total phenolics (TPh), total flavonoids (TFd) content, and TFd/TPh, the ratio of TFd in relation to $\mathrm{TPh}$ (Table 1$)$.

$\mathrm{TPh}$ and TFd increased with increasing concentration of apricots in honey. In comparison to honey, TPh increased from 61.07 to $111.94 \mathrm{mg}$ GAE/100 g honey for PH40 (1.86 times). After one-year storage, TPh of polyfloral honey increased slightly lower (1.77 times) from 60.19 for PH40s to $106.46 \mathrm{mg}$ GAE/100 g honey compared to PHs. TFd slightly increased, approximately 3.23-fold, from 2.39 for $\mathrm{PH}$ to $7.72 \mathrm{mg}$ RE/100 g honey for PH40. Polyfloral honey after oneyear storage showed TFd increase of 5.15-fold, from 2.01 for PHs to $10.36 \mathrm{mg}$ RE/100 g honey for PH40s.

The amount of polyphenols in honeys is closely related not only to the floral variety but also to specific parameters, such as soil composition and meteorological conditions. Thus, it is possible to relate the phenolic profiles of honeys of the same botanical source with their geographical origin $[21,22]$. Based on spectrophotometric determination, it can be concluded that samples of polyfloral honey with dried
TABle 1: Polyphenolic composition of honey samples.

\begin{tabular}{lccc}
\hline Sample & $\begin{array}{c}\text { TPh } \\
(\mathrm{mg} \mathrm{GAE} / 100 \mathrm{~g})^{1}\end{array}$ & $\begin{array}{c}\text { TFd } \\
(\mathrm{mg} \mathrm{RE} / 100 \mathrm{~g})^{2}\end{array}$ & TFd/TPh $^{3}$ \\
\hline PH & $61.07 \pm 3.01^{\mathrm{aa}}$ & $2.39 \pm 0.09^{\mathrm{a}}$ & 0.04 \\
PH20 & $61.99 \pm 2.98^{\mathrm{a}}$ & $5.90 \pm 0.24^{\mathrm{a}}$ & 0.10 \\
PH30 & $85.25 \pm 4.02^{\mathrm{b}}$ & $6.27 \pm 0.26^{\mathrm{a}}$ & 0.07 \\
PH40 & $111.94 \pm 5.21^{\mathrm{c}}$ & $7.72 \pm 0.31^{\mathrm{a}}$ & 0.07 \\
PHs & $60.19 \pm 3.00^{\mathrm{a}}$ & $2.01 \pm 0.10^{\mathrm{b}}$ & 0.03 \\
PH20s & $63.64 \pm 3.51^{\mathrm{a}}$ & $5.68 \pm 0.11^{\mathrm{a}}$ & 0.09 \\
PH30s & $79.42 \pm 0.69^{\mathrm{b}}$ & $6.83 \pm 0.07^{\mathrm{a}}$ & 0.09 \\
PH40s & $106.46 \pm 1.49^{\mathrm{c}}$ & $10.36 \pm 0.05^{\mathrm{a}}$ & 0.10 \\
\hline
\end{tabular}

${ }^{1}$ Total phenol content expressed as mg gallic acid equivalents per $100 \mathrm{~g}$ of honey sample; ${ }^{2}$ total flavonoid content expressed as mg rutin equivalents per $100 \mathrm{~g}$ of honey sample; ${ }^{3} \mathrm{TFd} / \mathrm{TPh}$ : the ratio of TFd in relation to $\mathrm{TPh}$. TPh and TFd values are mean \pm SD of three replicates. ${ }^{4}$ Values sharing the same letters in the same row are not significantly different from each other at the level of $5 \%$.

apricot possess higher content of polyphenolics in comparison to honey. Also, honey samples after storage remained almost of the same polyphenols content, like before storage time, probably because the antioxidant compounds present in dried apricots aided in the maintenance of the honey properties along one year of storage.

The antioxidant activities of food and food extracts cannot be evaluated by a single method, but at least two test systems have been recommended for the determination of antioxidant activity to establish authenticity [23]. In our study we assessed three different antioxidant tests to determine the activity of honey samples. ESR spectroscopy, an analytical method for direct detection of free radicals, was used to determine decrease of hydroxyl radical concentration. Hydroxyl radicals are major reactive oxygen species inducing biological damage and lipid peroxidation. This radical is produced from hydrogen and ferrous ions via the Fenton reaction. The decrease in DPPH radical concentration as well as reducing power was determined spectrophotometrically. The antioxidant molecules can quench DPPH free radicals (i.e., by providing hydrogen atoms or by electron donation, conceivably via a free-radical attack on the DPPH molecule) and convert them to a colorless/bleached product (i.e., 2,2diphenyl-1-hydrazyne or a substituted analogous hydrazine), resulting in a decrease in the absorbance at $517 \mathrm{~nm}$ [24]. The reducing power of honey samples may serve as a significant indicator of their potential antioxidant activity. Based on measuring the reduction of ferric-ferrous transitions, the reducing power of honey samples was determined.

The honey with dried apricots exhibited higher antioxidant activity than honey without dried apricots, while the honeys after one-year storage did not exhibit big changes in antioxidant activity. Čanadanović-Brunet et al. [25] showed that dried apricot has good antioxidant activity and that phenolic compounds in dried apricot appear to be the main contributors to their antioxidant capacity. Ćetković et al. [26] reported that antioxidant activity increased with increasing the concentration of dried apricots in honey and that it could be explained by the fact that bioactive components of dried 
TABLE 2: Antioxidant activities of honey samples.

\begin{tabular}{lccc}
\hline Sample & $\begin{array}{c}\mathrm{EC}_{50} \mathrm{OH} \\
(\mathrm{mg} / \mathrm{mL})^{1}\end{array}$ & $\begin{array}{c}\mathrm{EC}_{50}{ }^{\mathrm{DPH}} \\
(\mathrm{mg} / \mathrm{mL})^{2}\end{array}$ & $\begin{array}{c}\mathrm{RP}_{0.5} \\
(\mathrm{mg} / \mathrm{mL})^{3}\end{array}$ \\
\hline PH & $3.36 \pm 0.13^{4 \mathrm{a}}$ & $30.60 \pm 1.48^{\mathrm{a}}$ & $66.37 \pm 3.01^{\mathrm{a}}$ \\
PH20 & $3.12 \pm 0.10^{\mathrm{ab}}$ & $27.29 \pm 1.19^{\mathrm{ab}}$ & $46.42 \pm 1.98^{\mathrm{b}}$ \\
PH30 & $2.52 \pm 0.08^{\mathrm{c}}$ & $21.91 \pm 1.00^{\mathrm{d}}$ & $44.65 \pm 2.15^{\mathrm{b}}$ \\
PH40 & $2.29 \pm 0.08^{\mathrm{c}}$ & $14.95 \pm 1.68^{\mathrm{c}}$ & $31.83 \pm 1.40^{\mathrm{c}}$ \\
PHs & $3.48 \pm 0.15^{\mathrm{a}}$ & $31.22 \pm 1.49^{\mathrm{a}}$ & $67.99 \pm 3.28^{\mathrm{a}}$ \\
PH20s & $3.01 \pm 0.11^{\mathrm{bd}}$ & $29.77 \pm 1.63^{\mathrm{ab}}$ & $48.94 \pm 2.03^{\mathrm{b}}$ \\
PH30s & $2.88 \pm 0.09^{\mathrm{bd}}$ & $26.45 \pm 1.14^{\mathrm{b}}$ & $46.20 \pm 1.95^{\mathrm{b}}$ \\
PH40s & $2.68 \pm 0.10^{\mathrm{c}}$ & $17.43 \pm 1.03^{\mathrm{c}}$ & $35.03 \pm 1.58^{\mathrm{c}}$ \\
\hline
\end{tabular}

${ }^{1,2}$ The concentration of antioxidant necessary to decrease the initial concentration of hydroxyl/DPPH radicals by $50 \%$; ${ }^{3}$ the concentration of antioxidant assigned at 0.5 value of absorption; $\mathrm{EC}_{50}{ }^{\mathrm{OH}}, \mathrm{EC}_{50}{ }^{\mathrm{DPPH}}$, and $\mathrm{RP}_{0.5}$ values are mean $\pm \mathrm{SD}$ of three replicates. ${ }^{4}$ Values sharing the same letters in the same row are not significantly different from each other at the level of $5 \%$.

apricot were transferred to honey. Also, the same trend of honey samples antiradical activity remained after storage period.

Antioxidant activities were expressed as $\mathrm{EC}_{50}$ value (the concentration of antioxidant necessary to decrease the initial concentration of hydroxyl or DPPH radicals by $50 \%$; for RP it is the concentration of antioxidant assigned at 0.5 value of absorption) and results are presented in Table 2.

The $\mathrm{EC}_{50}{ }^{\mathrm{DPPH}}$ values ranged from 30.60 for $\mathrm{PH}$ to $14.95 \mathrm{mg} / \mathrm{mL}$ for PH40, while the $\mathrm{EC}_{50}{ }^{\mathrm{DPPH}}$ for PHs was 31.22 and PH40s was $17.43 \mathrm{mg} / \mathrm{mL}$, which is very close value like $\mathrm{EC}_{50}$ before storage time. $\mathrm{EC}_{50}{ }^{\mathrm{OH}}$ value for $\mathrm{PH}$ was $3.36 \mathrm{mg} / \mathrm{mL}$ and $2.29 \mathrm{mg} / \mathrm{mL}$ for PH40, while for PHs was 3.48 and $\mathrm{PH} 40$ s was $2.68 \mathrm{mg} / \mathrm{mL}$. $\mathrm{RP}_{0.5}$ values were $66.37 \mathrm{mg} / \mathrm{mL}$ for $\mathrm{PH}, 31.83 \mathrm{mg} / \mathrm{mL}$ for PH40, 67.99 for PHs, and 35.03 for PH40s.

It is interesting to consider that the several studies have shown there is a strong correlation between phenolics/flavonoids and antioxidant activities of honey samples $[27,28]$. For the correlation analysis, the $\mathrm{EC}_{50}$ values were transformed into their reciprocal values, $1 / \mathrm{EC}_{50} .1 / \mathrm{EC}_{50}$ is representative of the antioxidant activity because it follows the increasing trend of antioxidant efficiency (Figure 1).

Pearson's correlation coefficients $(R)$ between the composition and the antioxidant activities of honey samples are shown in Table 3.

The correlation coefficients reveal a very good correlation between the total phenolic contents and analyzed antioxidant activities of honey samples $(R=0.894$ for hydroxyl radical scavenging activity, 0.971 for DPPH radical scavenging activity, and 0.922 for reducing power). The correlation coefficients for the relation between analyzed antioxidant activities and flavonoids were slightly lower $(R=0.731$ for hydroxyl radical scavenging activity, 0.752 for DPPH radical scavenging activity, and 0.899 for reducing power). According to the $R$ values it can be concluded that phenolics and flavonoids seem to be relevant compounds in honeyparticipating antioxidant reactions. The antioxidant activity of phenolic compounds is due to their ability to scavenge free

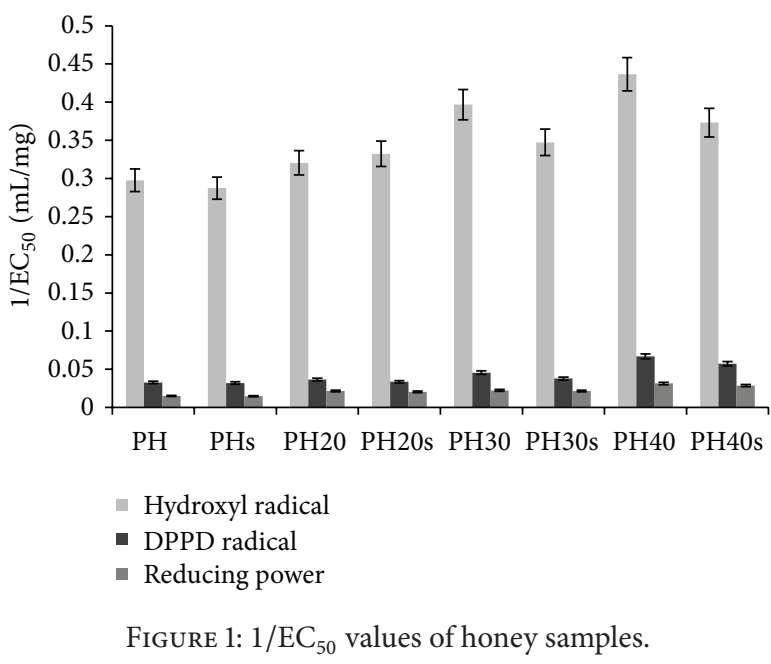

radicals, donate hydrogen atoms or electron, or chelate metal cations.

Used in many fields, sensory analysis allows to establish the organoleptic profile of diverse products (foods, cosmetics, pharmaceuticals, textiles, household products) and can be useful in knowing how they are perceived by the consumer [20]. The color of honey is related to the content of phenolics, besides minerals and pollen [29]. Honey samples with and without dried apricots, before and after storage, were evaluated by a 7 -member trained expert descriptive attribute sensory panel. The sensory quality of honey samples was defined based on density, intensity of color, aroma, and odour. Samples were scored using the 0 to 3 intensity scale and results are presented in Figure 2.

Sensorial descriptive profiling of all honeys and honeybased products has indicated very good quality. Consumer evaluations of $\mathrm{PH}$ honey samples indicated that analyzed honeys with the highest content of dried apricots exhibited the best sensory properties. The addition of dried apricots to honey improved density, color, odour, and aroma of the products. The total sensory scores increased from 2.76 for $\mathrm{PH}$ to 2.90 for $\mathrm{PH} 40$ and from 2.7 for $\mathrm{PHs}$ to 2.85 for PH40s, which shows that the quality of honey samples was improved with addition of dried apricots. Polyfloral honeys with dried apricots had very good sensory quality, which proofs that addition of dried apricots did not decrease the sensory properties of pure honey, but also that good sensory characteristics of honey samples remained after one-year storage.

\section{Conclusion}

Based on the presented results, we can conclude that honey with dried apricots, before and after one-year storage, contains high amount of bioactive compounds, originating from honey itself and also from the added dried apricots. Experimental results and statistical analysis show that addition of dried apricots increases the honey's antioxidant activity, but also slightly affects sensory properties. Also, one-year storage of honey samples did not diminish products quality. High 
TABLE 3: Correlation matrix (Pearson's correlation coefficients) between the composition and the antioxidant activities of honey samples.

\begin{tabular}{|c|c|c|c|c|c|}
\hline & \multirow{2}{*}{ TPh (mg GAE/100 g) } & \multirow{2}{*}{ TFd (mg RE/100 g) } & \multicolumn{3}{|c|}{$1 / \mathrm{EC}_{50}(\mathrm{~mL} / \mathrm{mg})$} \\
\hline & & & $\cdot \mathrm{OH}$ & $\mathrm{DPPH}$ & RP \\
\hline \multicolumn{6}{|l|}{$1 / \mathrm{EC}_{50}(\mathrm{~mL} / \mathrm{mg})$} \\
\hline $\mathrm{RP}$ & 0.922 & 0.899 & 0.895 & 0.936 & - \\
\hline DPPH & 0.971 & 0.752 & 0.897 & - & \\
\hline$\cdot \mathrm{OH}$ & 0.894 & 0.731 & - & & \\
\hline TFd (mg RE/100 g) & 0.814 & - & & & \\
\hline TPh (mg GAE/100 g) & - & & & & \\
\hline
\end{tabular}

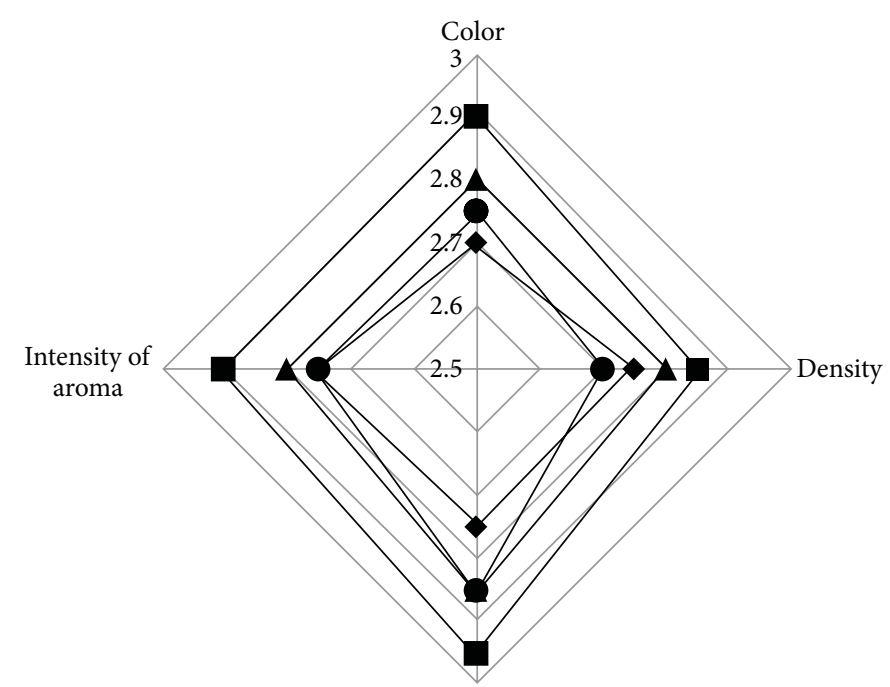

Intensity of odour

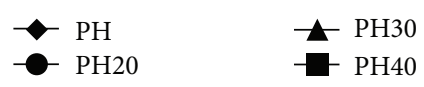

(a)

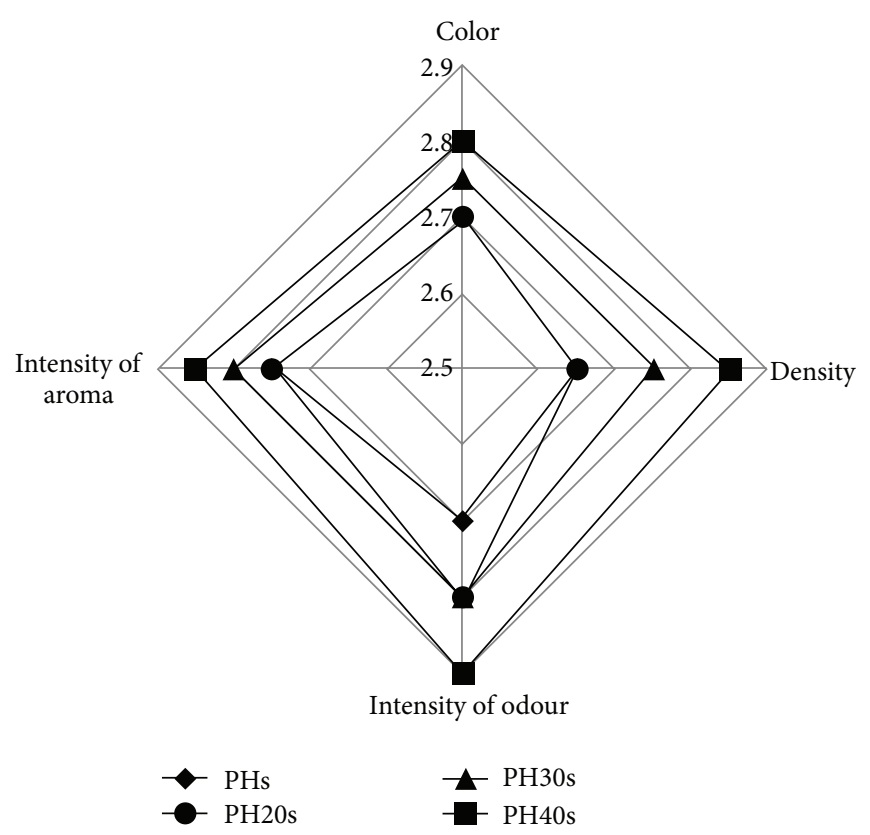

(b)

FIGURE 2: Sensorial characteristics of honey samples. (a) PH samples with addition of dried apricots; (b) PH samples with addition of dried apricots after one-year storage. Scores are means of seven evaluations by five panelists. Scores: 0 - unacceptable, 1-acceptable, 2-good, and 3-optimal quality level. 
level of correlation between phenolics/flavonoids content and antioxidant activities within all studied samples confirmed that they have good quality and present products with long shelf life in food industry.

\section{Conflict of Interests}

The authors declare that there is no conflict of interests regarding the publication of this paper.

\section{Acknowledgment}

This research is part of Project no. 114-451-1101/2014-02, which is financially supported by the Provincial Secretariat for Science and Technological Development of the Autonomous Province of Vojvodina, Serbia.

\section{References}

[1] J. Lachman, M. Orsák, A. Hejtmánková, and E. Kovářová, “Evaluation of antioxidant activity and total phenolics of selected Czech honeys," LWT_Food Science and Technology, vol. 43, no. 1, pp. 52-58, 2010.

[2] U. Gašić, S. Kečkeš, D. Dabić et al., "Phenolic profile and antioxidant activity of Serbian polyfloral honeys," Food Chemistry, vol. 145, pp. 599-607, 2014.

[3] The National Honey Board, "Honey-Health and therapeutic qualities," 390 Lashley Street Longmont, 2003, http://www.nhb .org/.

[4] L. Chen, A. Mehta, M. Berenbaum, A. R. Zangerl, and N. J. Engeseth, "Honeys from different floral sources as inhibitors of enzymatic browning in fruit and vegetable homogenates," Journal of Agricultural and Food Chemistry, vol. 48, no. 10, pp. 4997-5000, 2000.

[5] J. McKibben and N. J. Engeseth, "Honey as a protective agent against lipid oxidation in ground Turkey," Journal of Agricultural and Food Chemistry, vol. 50, no. 3, pp. 592-595, 2002.

[6] P. J. Taormina, B. A. Niemira, and L. R. Beuchat, "Inhibitory activity of honey against foodborne pathogens as influenced by the presence of hydrogen peroxide and level of antioxidant power," International Journal of Food Microbiology, vol. 69, no. 3, pp. 217-225, 2001.

[7] M. Blasa, M. Candiracci, A. Accorsi, M. P. Piacentini, M. C. Albertini, and E. Piatti, "Raw Millefiori honey is packed full of antioxidants," Food Chemistry, vol. 97, no. 2, pp. 217-222, 2006.

[8] C. Cimpoiu, A. Hosu, V. Miclaus, and A. Puscas, "Determination of the floral origin of some Romanian honeys on the basis of physical and biochemical properties," Spectrochimica ActaPart A: Molecular and Biomolecular Spectroscopy, vol. 100, pp. 149-154, 2013.

[9] J. de Bruijn and R. Bórquez, "Quality retention in strawberries dried by emerging dehydration methods," Food Research International, vol. 63, pp. 42-48, 2014.

[10] Y. Yilmaz and R. Toledo, "Antioxidant activity of water-soluble Maillard reaction products," Food Chemistry, vol. 93, no. 2, pp. 273-278, 2005.

[11] H. Hacıseferoğulları, I. Gezer, M. M. Özcan, and B. MuratAsma, "Post-harvest chemical and physical-mechanical properties of some apricot varieties cultivated in Turkey," Journal of Food Engineering, vol. 79, no. 1, pp. 364-373, 2007.
[12] S. Karav and A. Eksi, "Antioxidant capacity and total phenolic contents of peach and apricot cultivars harvested from different regions of Turkey," International Journal of Food and Nutrition Science, vol. 1, no. 13, 2012.

[13] K. Güçlü, M. Altun, M. Özyürek, S. E. Karademir, and R. Apak, "Antioxidant capacity of fresh, sun- and sulphited-dried Malatya apricot (Prunus armeniaca) assayed by CUPRAC, ABTS/TEAC and folin methods," International Journal of Food Science and Technology, vol. 41, no. 1, pp. 76-85, 2006.

[14] V. L. Singleton, R. Orthofer, and R. M. Lamuela-Raventos, "Methods in enzymology," in Oxidant and Antioxidant, Part A, L. Packer, Ed., vol. 299, p. 152, Academic Press, San Diego, Calif, USA, 1999.

[15] Z. Jia, M. Tang, and J. Wu, “The determination of flavonoid contents in mulberry and their scavenging effects on superoxide radicals," Food Chemistry, vol. 64, no. 4, pp. 555-559, 1999.

[16] ISO 8589, Sensory Analysis-General Guidance for the Design of Test Rooms, International Organization for Standardization, Geneva, Switzerland, 1988, http://www.iso.org.

[17] ISO, "Sensory analysis-methodology_-general guidance," ISO 6658, International Organization for Standardization, Geneva, Switzerland, 1985, http://www.iso.org/.

[18] ISO 8586-1, Sensory Analysis-General Guidance for the Selection, Training and Monitoring of Assessors-Part 1: Selected Assessors, International Organization for Standardization, Geneva, Switzerland, 1993, http://www.iso.org.

[19] ISO, "Sensory analysis-general guidance for the selection, training and monitoring of assessors-part 2: experts," ISO 8586-2, International Organization for Standardization, Geneva, Switzerland, 1994, http://www.iso.org.

[20] M. L. Piana, L. Persano Oddo, A. Bentabol, E. Bruneau, S. Bogdanov, and C. G. Declerck, "Sensory analysis applied to honey: state of the art," Apidologie, vol. 35, supplement 1, pp. S26-S37, 2004.

[21] N. Bilandžić, M. Dokić, M. Sedak et al., "Determination of trace elements in Croatian floral honey originating from different regions," Food Chemistry, vol. 128, no. 4, pp. 1160-1164, 2011.

[22] U. Kropf, J. Bertoncelj, M. Korošec et al., "Geographical origin of Slovenian multifloral and forest honey," Apiacta, vol. 44, pp. 33-42, 2009.

[23] K. Schlesier, M. Harwat, V. Böhm, and R. Bitsch, "Assessment of antioxidant activity by using different in vitro methods," Free Radical Research, vol. 36, no. 2, pp. 177-187, 2002.

[24] E. Işik, S. Şahin, C. Demir, and C. Türkben, "Determination of total phenolic content of raspberry and blackberry cultivars by immobilized horseradish peroxidase bioreactor," Journal of Food Composition and Analysis, vol. 24, no. 7, pp. 944-949, 2011.

[25] J. M. Čanadanović-Brunet, J. J. Vulić, G. S. Ćetković, S. M. Djilas, and V. T. T. Šaponjac, "Bioactive compounds and antioxidant properties of dried apricot," Acta Periodica Technologica, vol. 44, pp. 193-205, 2013.

[26] G. Ćetković, J. Čanadanović-Brunet, J. Vulić, S. Djilas, and V. T. Šaponjac, "Antioxidant and sensorial properties of linden honey with dried apricots," Chemistry \& Biodiversity, vol. 11, no. 11, pp. 1861-1870, 2014.

[27] V. T. Tumbas, J. J. Vulić, J. M. Čanadanović-Brunet et al., "Antioxidant and sensorial properties of acacia honey supplemented with prunes," Acta Periodica Technologica, vol. 43, pp. 293-304, 2012. 
[28] A. M. Aljadi and M. Y. Kamaruddin, "Evaluation of the phenolic contents and antioxidant capacities of two Malaysian floral honeys," Food Chemistry, vol. 85, no. 4, pp. 513-518, 2004.

[29] V. Baltrušaityte, P. R. Venskutonis, and V. Čeksteryte, "Radical scavenging activity of different floral origin honey and beebread phenolic extracts," Food Chemistry, vol. 101, no. 2, pp. 502-514, 2007. 

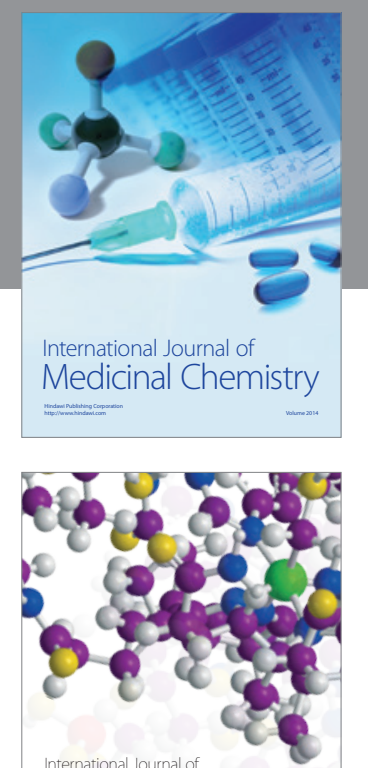

\section{Carbohydrate} Chemistry

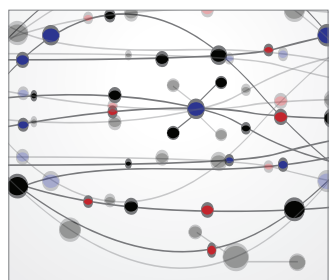

The Scientific World Journal
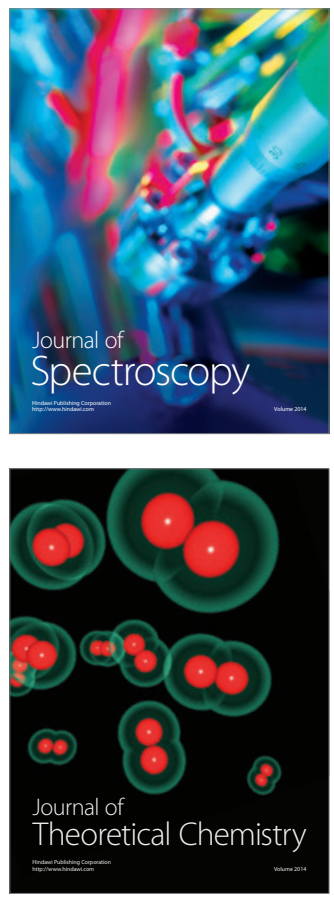
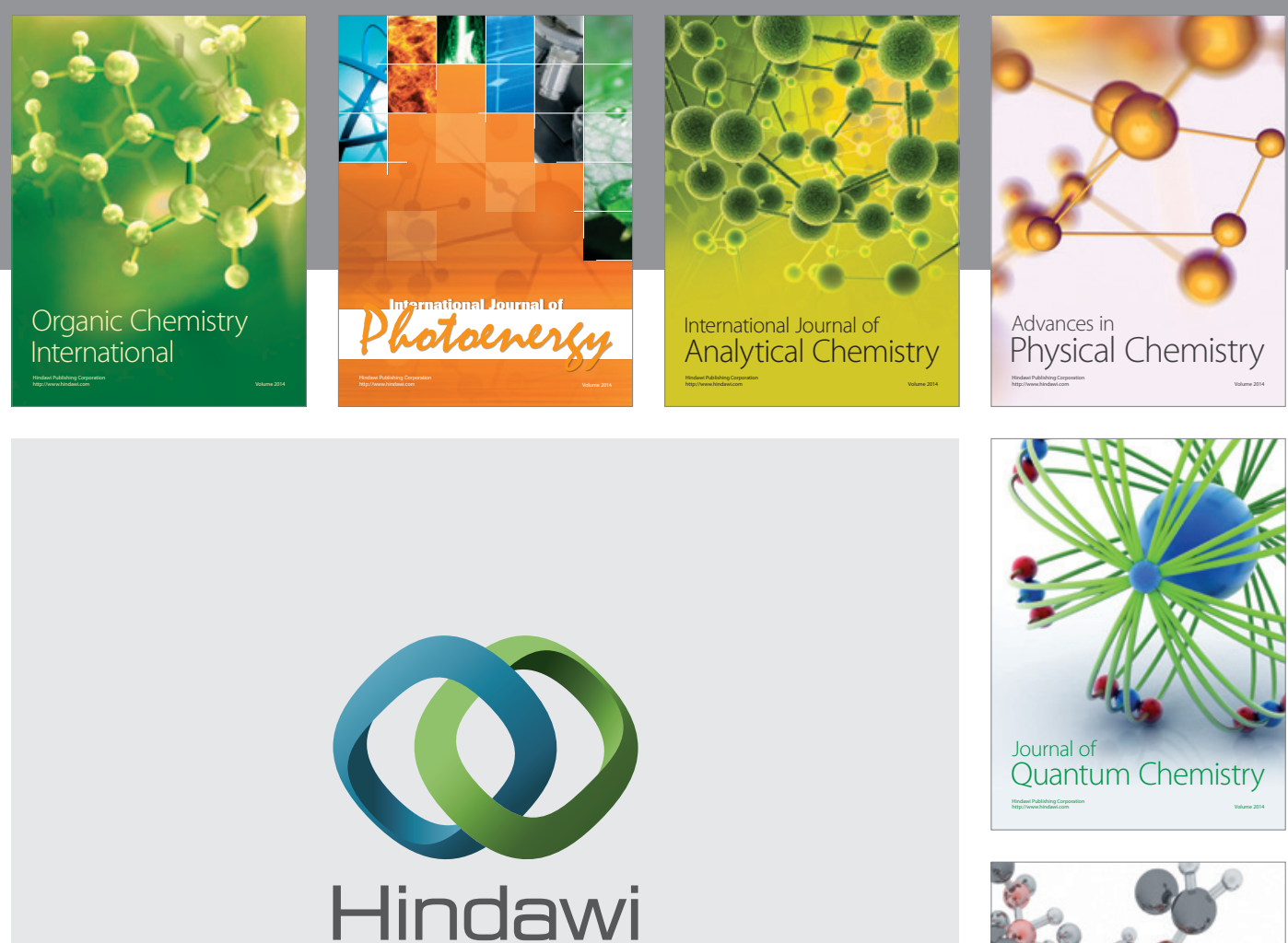

Submit your manuscripts at

http://www.hindawi.com

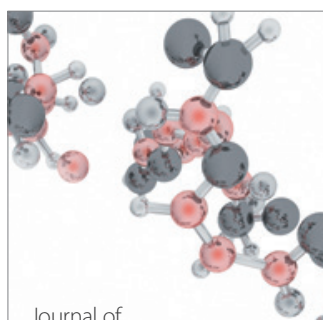

Analytical Methods

in Chemistry

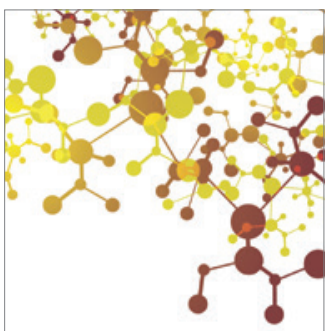

Journal of

Applied Chemistry

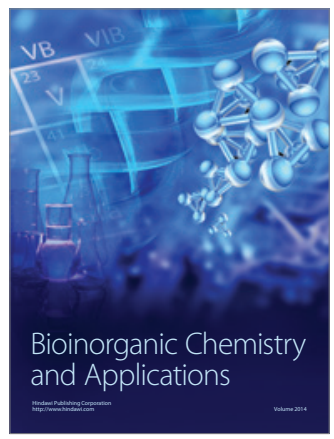

Inorganic Chemistry
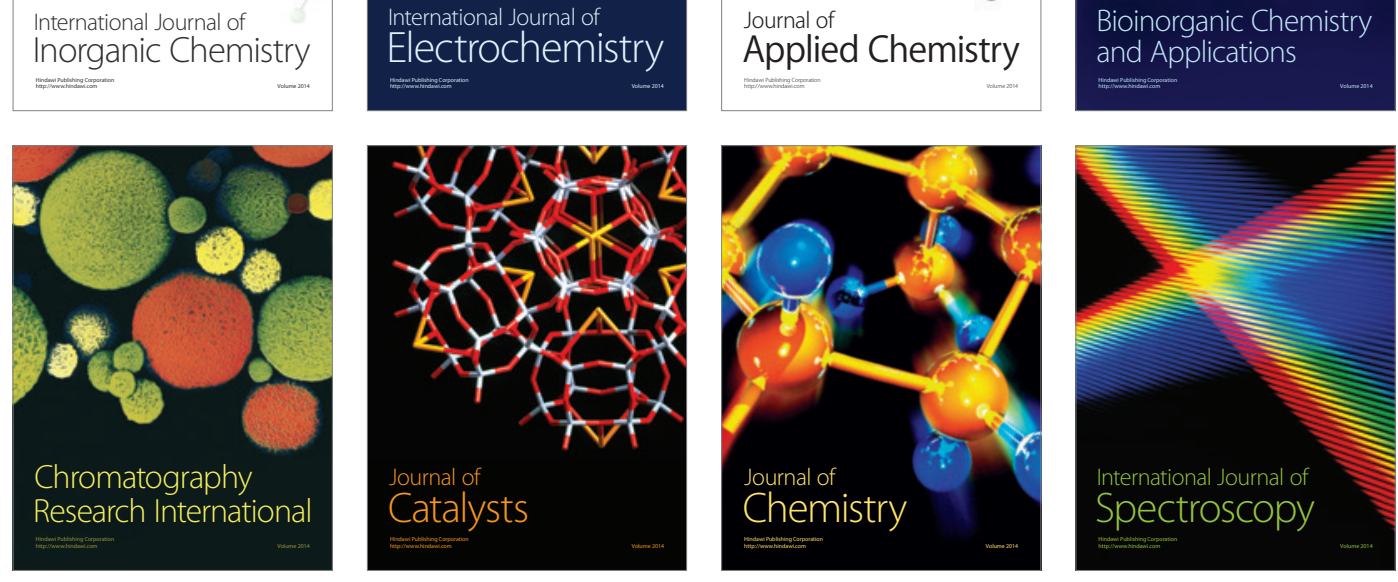